Procesos Urbanos Número 3:10-23; 2016. ISSN: 2422-085X

\title{
Acerca de las ciudades: la mirada de ayer y de hoy
}

\author{
About cities: the look of yesterday and today
}

\begin{abstract}
Alberto Saldarriaga Roa, ${ }^{1}$ Esp.
${ }^{1}$ Universidad de Bogotá Jorge Tadeo Lozano. Facultad de Artes y Diseño. Arquitecto, Especialista en Vivienda y Planeamiento en el Centro Interamericano de Vivienda en Bogotá. Correspondencia: facultad.artesdiseno@utadeo.edu.co
\end{abstract}

Recibido: 13 de julio 2016. Aceptado: 7 de septiembre de 2016.

Saldariaga, A. (2016). Acerca de las ciudades: la mirada de ayer y de hoy. Procesos urbanos Número 3, Ene-Dic. 10-23. Doi: $10.21892 / 2422085 X .264$

\section{RESUMEN}

En el título del artículo: "Acerca de las ciudades: la mirada de ayer y hoy" se intenta describir su contenido y el plano de observación de distintos planteamientos acerca de aquello que se ha entendido y juzgado como ciudad desde la segunda mitad del siglo XVIII hasta el presente. Se asume, como punto de partida, un artículo del historiador austríaco Carl Schorske, en el que se plantea como, desde las últimas décadas del siglo XVII hasta las primeras décadas de siglo $X X$, se advierten tres modos de mirar las ciudades, bien sea como espacios de virtud, de vicio o de algo "más allá del bien y del mal". En el texto se afirma que estos tres modos de mirar y juzgar las ciudades han perdurado a todo lo largo del siglo XX y aún en los inicios del siglo XXI. Para ello, se recorren las aproximaciones más significativas a los fenómenos urbanos, en especial a los conceptos de "metrópolis", "megalópolis" y su secuela, "ecumenópolis" que calificaron las ciudades en razón a su extensión y complejidad. A renglón seguido se da una lectura rápida a los planteamientos del grupo Team X en los que hay crítica a la ciudad funcional y propuestas dirigidas más hacia la experiencia de la ciudad que a unos esquemas abstractos. Se detallan dos propuestas "futuristas": la del Urbanismo Espacial" de Yona Friedmann y la de la "Arcología" de Paolo Soleri. Y, en una sección aparte, se estudian aproximaciones contemporáneas a las ciudades como espacios de "complejidad, multiculturalidad e información". Una breve sección propone interrogantes sobre la mirada a la ciudad latinoamericana, a partir de autores como José Luís Romero y Jacques Aprile Gniset. En la bibliografía se da cuenta de los textos consultados.

Palabras clave: Historia urbana, ciudades, metrópolis, megalópolis, ecumenópolis.

\section{ABSTRACT}

In the title of the article: "About the cities: the look of yesterday and today" is intended to describe its content and the plan of observation of different approaches about what has been understood and judged as a city since the second half of the eighteenth century until the present. As a starting point, an article by the Austrian historian Carl Schorske argues that, from the last decades of the seventeenth century to the first decades of the twentieth century, three ways of looking at cities are seen, either as spaces of virtue, vice or something "beyond good and evil". The text states that these three ways of looking at and judging cities have lasted throughout the twentieth century and even at the beginning of the twenty-first 
Saldarriaga, A. - Acerca de las ciudades: la mirada de ayer y de hoy.

century. The most significant approaches to urban phenomena, especially the concepts of "metropolis", "megalopolis" and its sequel, "ecumenopolis", which cities have been called, are considered because of their extension and complexity. The following section gives a quick reading of the Team $X$ proposals in which there is criticism of the functional city and proposals directed more towards the experience of the city than to abstract schemes. Two "futuristic" proposals are described: "Spatial Urbanism", by Yona Friedmann and "Arcología", by Paolo Soleri. In a separate section, contemporary approaches to cities are studied as spaces of "complexity, multiculturality and information". A brief section proposes questions about the look at the Latin American city, based on authors such as José Luís Romero and Jacques Aprile Gniset. In the bibliography, the texts consulted are reported.

Keywords: Urban history, cities, metropolis, megalopolis, ecumenopolis.

\section{Introducción}

En un ensayo titulado "The Idea of the City in European Thought: Voltaire to Spengler" el historiador austríaco Carl Schorske propuso una interpretación interesante acerca de lo que se pensó en Europa sobre la ciudad desde el final del siglo XVIII hasta el inicio del siglo $X X$ :

"Es posible, creo, discernir tres amplias evaluaciones de la ciudad en los pasados doscientos años: la ciudad como virtud, la ciudad como vicio y la ciudad más allá del bien y del mal. Estas concepciones aparecen en pensadores y artistas en sucesión temporal. El siglo dieciocho desarrolló a partir de la filosofía del Iluminismo la visión de la ciudad como virtud. El Industrialismo a principios del siglo diecinueve puso en primer plano una concepción antitética: la ciudad como vicio. Finalmente emergió, en el contexto de una nueva cultura subjetivista nacida a mediados del siglo diecinueve, una actitud intelectual que ubicó la ciudad más allá del bien y del mal. Ninguna fase nueva destruyó su antecesora, Cada una vivió hasta adentrarse en las fases que la sucedieron, pero con su vitalidad debilitada, su brillo descolorido. Las diferencias en el desarrollo nacional, tanto social como intelectual, hacen difusa la claridad de los temas. Aún más, mientras las décadas pasan, esquemas de pensamiento una vez enfocados como antitéticos se entretejen para formar nuevos puntos de partida para el pensamiento sobre la ciudad. En la historia de la idea de ciudad, como en otras ramas de la historia, comúnmente lo nuevo alimenta lo viejo más de lo que lo destruye." (Schorske, 2000, p.111).
En cada uno de los tres momentos del pensamiento europeo sobre ciudad, Shorske señala los autores en su concepto más representativos. En el primero, las virtudes de la ciudad, figuran tres autores: Voltaire, Adam Smith y Johann Gottlieb Fichte, cuyos planteamientos comparten principalmente la idea de la ciudad como cuna y territorio del progreso y de la civilización. La visión de la ciudad como vicio se formó, según Schorske, a la par con la expansión del industrialismo en la primera mitad del siglo diecinueve, la que dio origen a la "ciudad industrial" en la que los ideales del Iluminismo se desvanecieron. Los autores listados por Schorske se dividen entre los "arcaistas" y los "futuristas",. Entre los primeros menciona a Coleridge, John Ruskin, los prerrafaelitas, Dostoyevsky y Tolstoi, con una actitud de rechazo hacia la ciudad industrial y la búsqueda de un retorno a la sociedad agraria y los pequeños centros urbanos. Entre los futuristas o reformadores, Marx y Engels y las ideas socialistas ocupan un lugar preeminente, con su atención puesta en la ciudad como escenario de la opresión laboral, al tiempo que Engels la veía como el escenario de la liberación del proletariado. Ambos coincidieron en la necesidad de "abolición del contraste entre ciudad y campo". Las comunidades ideales de Owen y Fourier fueron vistas como la síntesis equilibrada entre lo urbano y lo rural. (Schorske, 2000, p.108)

En último término Schorske señala cómo, en la segunda mitad del siglo diecinueve,... "surgió en Francia un nuevo modo de pensamiento y sentir que ha extendido lenta pero poderosamente su influencia sobre las conciencias de occidente". Esta sería la visión de la ciudad "más allá del bien y del mal", que

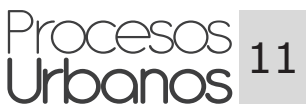


se encuentra en la génesis de la idea moderna de ciudad. A la pregunta de cque caracteriza esta mirada? Schorske responde:... "Qué es moderno? Los transvaluadores intelectuales dieron un nuevo enfoque a la pregunta. No se preguntaron ¿Qué es bueno y malo respecto a la vida moderna? sino ¿Qué es ella? ¿Qué es verdadero, qué falso? Entre las verdades que encontraron estaba la ciudad, con todas sus glorias y horrores, sus bellezas y sus fealdades, como el terreno esencial de la existencia moderna. No juzgarla éticamente, sino experimentarla plenamente en la propia persona se convirtió en la meta de los novi homines de la cultura moderna" (Schorke, 2000, p.111)

Dos autores son estudiados con cierto detalle por Schorsrke en relación con esta tercera visión de la ciudad. El primero es Charles Baudelaire y el segundo es Oswald Spengler. Al primero le reconoce haber visto en la ciudad una experiencia inédita a la que aplica conceptos tales como "multitud y soledad", "un ebrio encantamiento de vitalidad", "febriles alegrías que siempre le serán negadas al egoista"...Añade Schorske: "Para Baudelaire y los estetas del fin de siécle y los decadentes que le siguieron, la ciudad hacía posible lo que Walter Pater llamó "la veloz conciencia multiplicada". Este enriquecimiento de la sensibilidad personal, sin embargo, era adquirida a un precio terrible: el desprendimiento de las comodidades psicológicas de la tradición y de cualquier sentido de participación en un todo social integrado" (Schorske, 2000, p.112) La gran ciudad, surgida en la era industrial, era al mismo tiempo infierno y paraíso, esos juicios ya no eran significativos.

Spengler es para Schorske ... "el más brillante de los historiadores de la ciudad". Su pensamiento era afín a los de Fichte, Voltaire, Verheaeren, Baudelaire, Trilkes Y le Gallienne, pero..."se diferenciaba de ellos en el área más crucial: transformó todas sus afirmaciones en negaciones. Este, el más brillante de todos los historiadores de la ciudad, odiaba su sujeto con toda la pasión de los neoarcaístas del fin de siécle, los derechistas antidemocráticos frustrados de la baja clase media. Aunque presentaba la ciudad como fatalidad, claramente daba la bienvenida a su muerte." (Schorske, 2000, p.115)

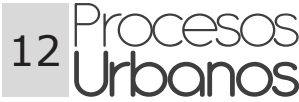

En algo más de un siglo, quienes pensaron sobre la ciudad destacaron su papel en el curso de la civilización occidental, su descomposición vía industrialización y la superación de sus vicios y virtudes gracias a la seducción de la intensidad de su experiencia. Si bien Schorske se refiere a ideas que surgieron en Europa a lo largo de algo más de un siglo, los tres enfoques señalados han persistido en la mirada a las ciudades a lo largo del siglo veinte e incluso a inicios del veintiuno. Hay todavía quienes ven en la ciudad el lugar del progreso y de la civilización, quienes la ven como el escenario de los horrores de la vida moderna regida, bien sea por el capitalismo o por el socialismo y quienes en vez de juzgarla, buscan explicar su complejidad y dar cuenta de su papel en ese vasto mosaico que puede llamarse "vida contemporánea".

\section{¿De qué ciudad se habla?}

Schorske claramente trata en su texto la idea de ciudad en Europa entre el final del siglo XVIII y el inicio del XX. La ciudad europea se convirtió rápidamente en el soporte de la idea de la "ciudad occidental", denominación asociada a unos límites territoriales y una genealogía cuyas trazas más antiguas se sitúan en la Grecia clásica y se prologan en la Roma imperial, en la ciudad medieval, renacentista y barroca, hasta llegar a la Ilustración y sus derivaciones en la ciudad industrial y la ciudad moderna. La construcción de este gran discurso histórico hace pensar en una continuidad evolutiva, la que al ser vista de cerca muestra la presencia de discontinuidades y alteraciones. El eje de este discurso es el mismo de la formación y desarrollo de la "civilización occidental" término que terminó de acuñarse en el siglo XIX en el que intervienen, además de lo material, factores de orden político, económico y cultural. Es un discurso complejo que ha influido directamente en la construcción de discursos análogos en, por ejemplo, el estudio de la "ciudad latinoamericana" o "hispanoamericana" o "colombiana"

La ruptura de la modernidad con el historicismo dio pie a la construcción de nuevas ideas y discursos acerca de los fenómenos urbanos en las que la mirada a la ciudad adquiere nuevos sentidos. Dos de ellas las de "metrópoli" y "megalópolis", han perdurado a lo largo del 
siglo XX. El sociólogo alemán Georg Simmel fue uno de los primeros en reconocer que algo había cambiado en las grandes ciudades a partir de la industrialización. Su aproximación se apoya en la idea de ... "la intensificación de la estimulación nerviosa que deriva del cambio acelerado y sin interrupciones de estímulos internos y externos" (...). Impresiones duraderas, impresiones que solo difieren ligeramente ente ellas, impresiones que toman un curso regular y habitual y presentan contrastes regulares y habituales; - todas ellas usan, por así decirlo, menos conciencia que la rápida aglomeración de imágenes cambiantes, la aguda discontinuidad en la captura de una sola mirada y lo inesperado de impresiones apresuradas. Esas son las condiciones psicológicas que crea la vida metropolitana." (Simmel, 1950, p.410). Simmel expande esa idea a la vida metropolitana. "Así la vida metropolitana sostiene una conciencia elevada y una predominancia de la inteligencia en el ser metropolitano", pero la metrópolis, además de ser un fenómeno mental, es un mundo predominantemente económico..."Solo la economía del dinero ha llenado los días de tanta gente con la medición de los pesos, con el cálculo, con determinaciones numéricas, con una reducción de los valores cualitativos en favor de los cuantitativos. A través de la naturaleza calculadora del dinero una nueva precisión, una certeza en la definición de identidades y diferencias, ha aparecido en las relaciones de los elementos de la vida una ausencia de ambigüedad en acuerdos y arreglos - de la misma manera como externamente esta precisión ha sido efectuada a través de la difusión universal del reloj de bolsillo." (Simmel, 1950)

El texto citado de Simmel es uno de los pilares de la sociología urbana moderna y su autor fue uno de los primeros en reconocer en la metrópoli, como anteriormente lo hizo Baudelaire, una nueva forma de vida y el surgimiento de una nueva individualidad, tras la cual existe una enorme maquinaria económica que impone sus reglas sobre todos los aspectos de la vida metropolitana y de ella derivan todas sus virtudes y defectos. Sin referencias explícitas a una estructura física, en la visión de Simmel se perfilan las virtudes y los vicios futuros de la metrópoli moderna.
A lo largo del siglo XX el término "metrópoli" dejó de entenderse únicamente como un fenómeno socialmente complejo, como Simmel lo planteó, y se añadió la idea de una formación urbana de grandes dimensiones, en la que se reunían los restos de su pasado con nuevas dinámicas que la proyectaban hacia el futuro. Lewis Mumford, admirador de la ciudad histórica y adalid de una nueva ciudad, expresó sus inquietudes respecto a la ciudad que se formaba con esas nuevas dinámicas:

"Nadie puede estar satisfecho con la forma actual de la ciudad. Ni como un mecanismo de trabajo, ni como medio social, ni como obra de arte, la ciudad satisface las altas expectativas que la civilización moderna ha propuesto - ni siquiera da cuenta de nuestras demandas razonables. Sin embargo el proceso mecánico de fabricación de las estructuras urbanas nunca antes había alcanzado un punto tan alto: las energías que incluso una pequeña ciudad maneja, habría despertado la envidia de un faraón egipcio en la era de las pirámides. $Y$ hay momentos en los que al acercarse en automóvil a Nueva York, Filadelfia o San Francisco, si la luz es la correcta y las masas distantes de los edificios se encuentran suficientemente lejos, una nueva forma de esplendor urbano, más deslumbrante que el de Venecia o Florencia parecen haber alcanzado." (Mumford, 1968, p.21).

Kevin Lynch, por su parte, consideró que:

"Se dice a menudo que la metrópolis de hoy es deficiente como un ambiente habitable. Ha sufrido de un desarrollo incontrolado, de un crecimiento y cambio acelerados, de obsolescencia e inestabilidad. La circulación es congestionada, exigiendo un tiempo sustancial y un esfuerzo mayor. La accesibilidad es dispareja, particularmente a las abiertas áreas rurales. El uso de los equipamientos es desbalanceado y estos se convierten crecientemente en obsoletos. La segregación residencial de acuerdo con los grupos sociales parece crecer, en tanto que la escogencia de lugar de residencia para el individuo permanece restringida y no es satisfactoria. La estructura de actividades es inestable y sus costos de funcionamiento son altos. Visualmente, la ciudad carece de

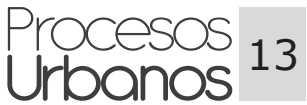


carácter y es confusa, lo mismo que ruidosa y poco confortable." (Lynch, 1968, p.97).

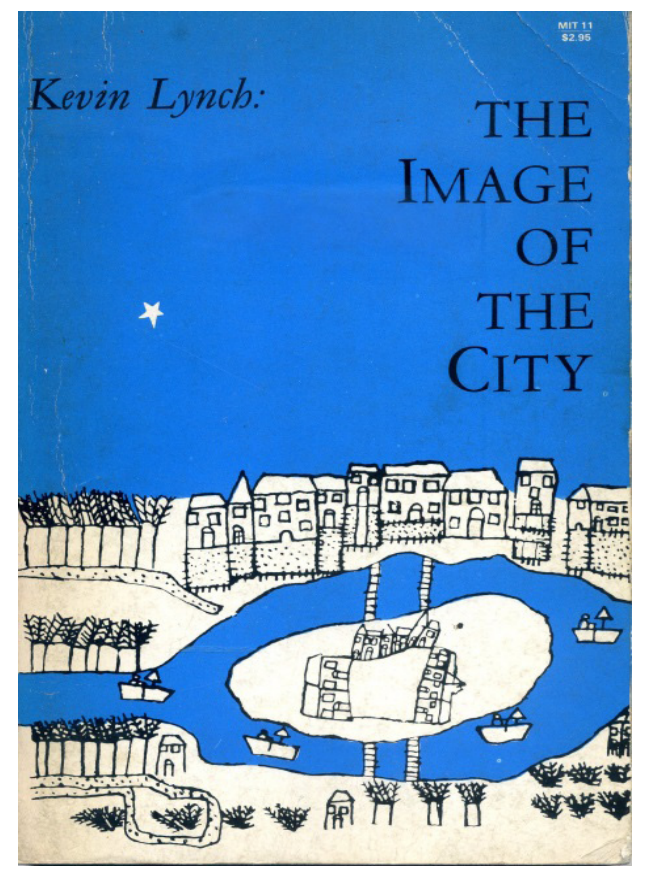

Figura 1. Carátula libro. Kevin Lynch.

Fuente: The Image of the City. M.I.T Press, Cambridge, 1960.

La idea de metrópolis había sido apropiada por urbanistas y críticos de los Estados Unidos para referirse a los fenómenos urbanos de ese país, los dos autores citados son ejemplo de ello. La idea de "Megalópolis" tuvo su origen en ese mismo escenario. El término se acuñó para calificar un tejido urbano de gran extensión, que desbordaba el tamaño de población más allá de los diez millones de habitantes. La idea y su explicación se deben al urbanista francés Jean Gottmann quien lo desarrolló en un estudio sobre la urbanización de la parte superior de la costa este de los Estados Unidos. Para este autor, la megalópolis estadounidense no era una ciudad única, sino el resultado de la continuidad de tejidos urbanos presente desde Boston hasta Washington. (Gottmann, 1961) Posteriormente el uso del término se expandió para abarcar formaciones urbanas de gigantescas dimensiones físicas y demográficas, como por ejemplo México D.F. Sao Paulo, Los Ángeles, Tokio o Calcuta.

Megalópolis no es una idea de forma urbana, trata principalmente de extensión y tamaño poblacional y por ende de la complejidad derivada de esos dos factores. El concepto se expandió posteriormente a la "Ecumenópolis", término acuñado en el libro Ekistics. The Science of Human Settlements por el arquitecto urbanista griego Constantinos Doxiadis que sugiere la formación del futuro de una ciudad continua extendida como una capa construida sobre el territorio geográfico. La Ecumenópolis de Doxiadis representa la expansión, al límite de la pesadilla, del modelo del suburbio norteamericano (Doxiadis, 1970).

Tanto las metrópolis como las megalópolis se desarrollaron como una sumatoria de expansiones periféricas de centros urbanos existentes. En ellas se adoptaron nuevas formas de movilidad, por ejemplo, tranvías y trenes subterráneos, automóviles y autopistas y se originaron nuevas concepciones espaciales de la ciudad del futuro. Las propuestas urbanas de las grandes personalidades de la arquitectura moderna dieron forma a sus visiones del fenómeno metropolitano, desde la Citta Nuova de los futuristas italianos hasta Broadacre City de Frank Lloyd Wright, la ciudad contemporánea y la Ville Radieuse de La Corbusier y la ciudad de rascacielos de Ludwig Hilberseimer. Estas propuestas nunca se concretaron en su forma original, pero influyeron considerablemente en el pensamiento espacial de la ciudad del siglo XX y pasaron posteriormente a calificarse como las utopías urbanas de la modernidad. Como se verá más adelante, otras propuestas posteriores recuperaron la imagen espacial de la ciudad del futuro.

Jean Gottman sintetizó el problema urbano originado en la primera mitad del siglo XX en los siguientes términos:

"La humanidad está recomponiendo su hábitat: La tendencia muy maligna hacia la urbanización ha llegado a ser tan rápida y masiva que ensombrece muchos otros problemas modernos. Los críticos de la urbanización moderna son muchos. Mucho de lo que dicen es correcto, pero los paralelos que trazan con casos del pasado a duras penas aplican. La ciudad moderna adquiere un volumen que requiere nuevos conceptos a la par de nuevos métodos. El cambio de escala produce un cambio en la naturaleza de los problemas de la ciudad y en la 
naturaleza de la planeación necesaria para satisfacer las necesidades de la población urbana..." (Gottman, 1968, p.7)

\section{Ideas sobre el presente y el futuro}

Entre 1960 y 1980 se produjo una oleada de propuestas urbanas orientadas al menos en dos corrientes diferentes. La primera de ellas, liderada por el grupo del Team X, reconoció la presencia del pasado en la ciudad y a la par de algunos urbanistas italianos, se reconoció el valor del patrimonio construido en el tejido de la ciudad moderna, contradiciendo abiertamente los postulados de la Carta de Atenas, documento de cabecera del urbanismo moderno. En el manual del Team X, organizado en forma de textos entretejidos de los diversos participantes del grupo, se reunió un conjunto apreciable de ideas y propuestas acerca de la vivienda y de la ciudad. En estas consideraciones se combinaron la crítica al urbanismo moderno, la valoración de la ciudad como hábitat humano y la visión de posibles transformaciones de la ciudad existente, un tema que no había preocupado al urbanismo moderno cuya meta era la total transformación urbana de acuerdo con sus postulados.

En uno de los apartes del manual del Team $X$ se lee:

"¿Pueden los arquitectos satisfacer la demanda plural de la sociedad? ¿Pueden acaso sustituir la pérdida presente de lo vernáculo y sin embargo construir una ciudad que sea realmente una ciudad, es decir, un lugar habitable para una multitud? Lo vernáculo pudo siempre hacer frente a la pluralidad en épocas pasadas. ¿En qué forma participará la gente en la conformación de su propio entorno inmediato dentro de un esquema general? Al decir "la ciudad", uno se refiere a la "gente" que vive en ella, y no simplemente a la "población". Este es el primer problema que enfrenta el arquitecto actual."

"Si la sociedad no tiene forma - cómo podrán los arquitectos construir la impronta de esa sociedad?

"Los arquitectos se han ocupado siempre de edificios aislados o de un complejo de edificios aislados".

"Creo que existe una paradoja implícita en las tareas del arquitecto de hoy en día". (van Eyck, Aldo, 1968, 31)

Al mismo tiempo en el Team $\mathrm{X}$ formularon serias críticas a la división, para ellos artificial, entre arquitectura y urbanismo. Según Aldo van Eyck:

"Creo que ha llegado el momento de abordar la arquitectura urbanísticamente y el urbanismo arquitectónicamente".

"La presente situación se debe, entre otras cosas, a una concepción errónea de la relación parte-todo. El resultado, por supuesto, es una arquitectura débil y un urbanismo atroz. (Mientras que los defectos de la mayoría de los edificios contemporáneos se deben a la indecisión con que el medio disponible ha sido entendido y manejado, el defecto de la mayor parte del urbanismo contemporáneo radica en la insuficiencia intrínseca de ese mismo medio disponible (aparte de la indiferencia con que ha sido comprendido y manejado). $Y$ esto me retrotrae a problema mismo del número y la multiplicidad. Hemos olvidado casi todo lo que habría que saber sobre la estética de la cosa única, mientras que conocemos poco todavía de la estética de las cosas múltiples." (Van Eyck, 1968, p.73)

En palabras de van Eyck, la ciudad existente a mediados del siglo XX era el resultado incompleto de la separación establecida entre la labor de los arquitectos y la de los urbanistas, unos a cargo de las partes, otros responsables del todo. Van Eyck pensaba en la ciudad como el punto de encuentro entre la arquitectura y el urbanismo, disciplinas que ya desde el final del siglo XIX se habían escindido. Van Eyck y el resto del grupo abogaban por una ciudad en la que los dos extremos hipotéticos -la parte y el todo- armonizaran. Esta idea era la antítesis del urbanismo funcionalista de la Carta de Atenas.

Una corriente diferente de ideas urbanas se formó casi a la par con el Team X. Su punto de 
convergencia fue la idea de "megaestructuras" urbanas que transformarían radicalmente la idea de ciudad hasta entonces vigente. En este grupo se encuentran, entre otras, las propuestas del grupo inglés Archigram, de los metabolistas japoneses, del arquitecto francés Yona Friedman y del arquitecto italiano Paolo Soleri. La motivación fue diversa, pero en ellas se conjugaron dos consideraciones: la preocupación por el futuro urbanizado del planeta y un alto grado de confianza en las nuevas posibilidades tecnológicas de construcción, movilidad y comunicación. Cada propuesta comprendía un planteamiento conceptual de soporte y unos esquemas arquitectónicos y modelos tridimensionales en los que se concretaban esos planteamientos. Dos ejemplos distintos ilustran esta corriente: el Urbanismo Móvil de Yona Friedman y la Arcología de Paolo Soleri.

En el Urbanismo móvil, Friedman propone algunas ideas claves:

"Los conceptos determinantes de la vida en sociedad están en perpetua transformación (organización y recreos)."(...) "Los conceptos de cohabitación familiar, así como los conceptos de cohabitación urbana (propiedad de terrenos urbanos comprendidos en su sentido actual) son obsoletos". (...)Las nuevas exigencias conducen a la búsqueda de la "movilidad" de la ciudad".

"Las nuevas construcciones que sirven como abrigos individuales deben:

Tocar el suelo en un mínimo de superficie.

Ser desmontables y desplazables.

Ser transformables a voluntad por el habitante individual."

"Los medios de circulación interior de la ciudad deben ser comunales: los automóviles y otros medios individuales de circular quedarán fuera de la ciudad y solo servirán para la circulación interurbana. La ciudad pertenece a los peatones. Su paso debe ser protegido del clima".

"Las estructuras se componen de un esqueleto tridimensional continuo, cuyos vacíos son utilizados como piezas; esas estructuras se llaman estructuras continente,

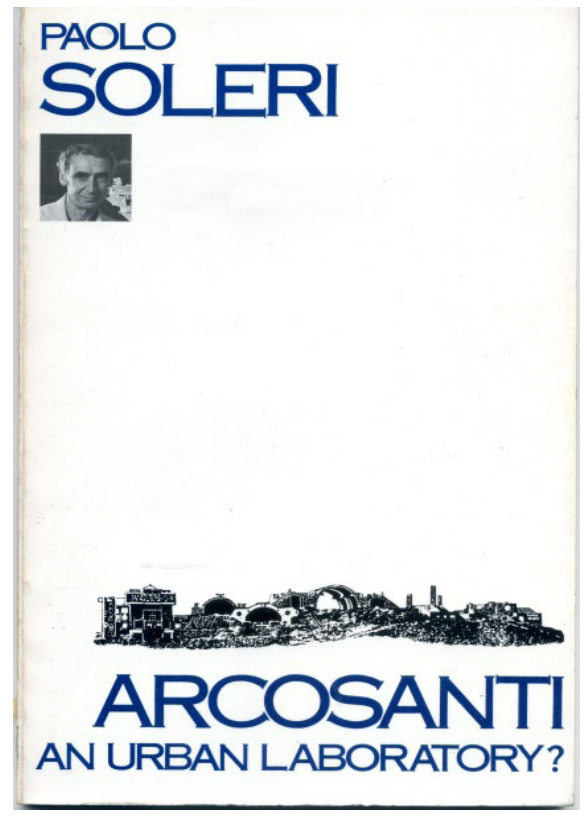

Figura 2. Carátula libro Paolo Soleri. Arcosanti. An Urban Laboratory?

Fuente: Avant Books, San Diego, 1984.

en relación con las demás estructuras que cargan las piezas, etc. y que componen una especia de plataforma. Estas últimas se llaman estructuras soporte". (Friedman, 1965, p.37)

La expresión física de las ideas de Friedman fue una de las grandes franjas de estructuras tridimensionales sin determinación alguna de uso. Era idea de una total indeterminación urbana y habitacional, alojada en los vacíos creados por dichas estructuras. No elaboró planos de una ciudad como tal, solo expresó sus ideas en esquemas sencillos.

En el enfoque de Paolo Soleri, los proyectos urbanos parten de un conjunto de consideraciones de perfil filosófico acerca del papel de las ciudades en la evolución futura de la humanidad. Para Soleri, es en las ciudades en donde se daría el siguiente paso evolutivo que él sintetiza en la frase "de la materia a la mente."

El recorrido de Soleri en el tema de las ciudades se inició en 1958 cuando propuso su primer 
proyecto de "mega" ciudad al que llamó Mesa City, que debía construirse en el desierto del suroeste de los Estados Unidos. Mesa City era una ciudad del conocimiento y su estructura urbana se basaba en unos grandes edificios de formas orgánicas, completamente extraños en su momento. En 1970 y simultáneamente con una gran exposición retrospectiva, publicó lo que sería su manifiesto urbano: Arcology. The City in the Image of Man, un libro de grandes dimensiones en el que se combinan su planteamiento filosófico con 30 ejemplos de "Arcologías", término con el que definió sus proyectos urbanos: edificaciones compactas y elevadas, mezcla de arquitectura y ecología. El punto de partida del libro se condensa en el siguiente párrafo:

"Constantinos Doxiadis presenta un mapa aterrador del mundo. El continente americano está cubierto con una especie de tejido que recuerda el de una tela oscura y desgarrada llevada por un torso fuerte. Los agujeros son grandes, pero son solo agujeros- El tejido oscuro es la ecumenópolis, la ciudad universal. Los agujeros son las áreas en las que la tierra respira y se renueva a sí misma. Un mapa de la desesperación. Doxiadis anticipa un continente transformado en el patio de atrás de la humanidad. Las abundantes hormigas humanas están por todas partes $y$ en todas partes son hormigas humanas. Los agujeros tampoco se salvarán. No serán bolsas de agricultura o de naturaleza virgen. Se salpicarán de subcolonias y serán semanalmente invadidas por olas de vacacionantes esquizofrénicos y estacionalmente inundadas por oleadas de suburbanitas dedicados a un nomadismo temporal" (Soleri, 1970, p.2).

Soleri reconocía que su visión del futuro urbanizado de la superficie del planeta, la Ecumenópolis de Doxiadis, era una expansión "ad infinitum" del modelo del suburbio estadounidense en el que el automóvil era protagonista. Ecumenópolis era la celebración de la suburbanización del planeta.

La lógica del planteamiento urbano de Soleri partió del rechazo a ese modelo y de la búsqueda la liberación de la existencia humana de la atadura a la superficie del planeta. Si el suburbio era una capa poblada adherida a esa superficie,

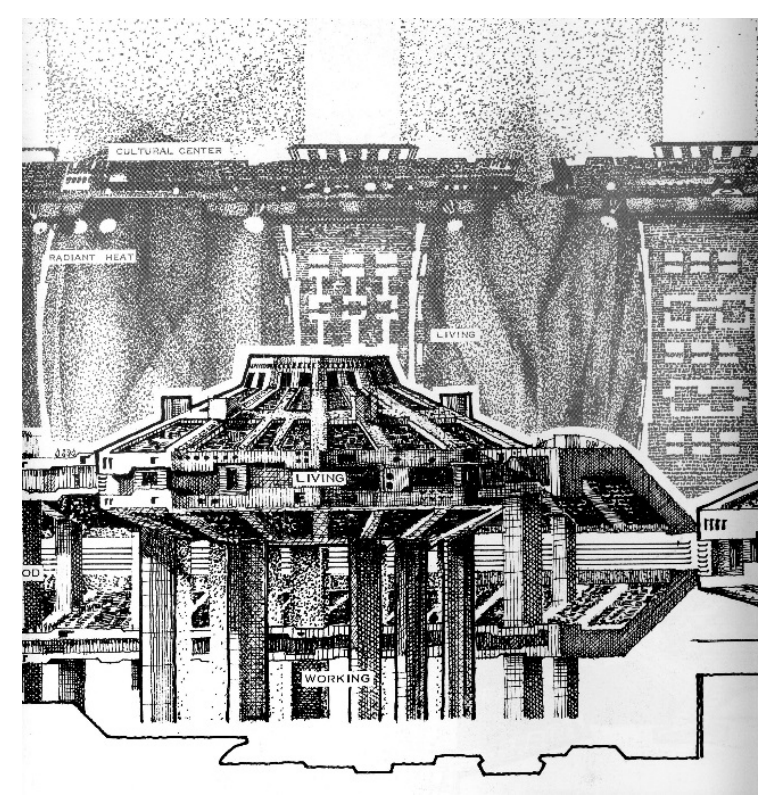

Figura 3. Arcología Babelnoah Fragmento.

Fuente: Soleri, Paolo, Arcology. The City in the Image of Man. M.I.T. Press, Cambridge, 1970

la propuesta de Soleri fue la de construir cien o más capas de acción superpuestas verticalmente, lo que podría representar la reducción a una mínima parte de la superficie expandida de la Ecumenópolis. El principio rector de ese encogimiento, según Soleri, es el de la "miniaturización", entendida no como un achicamiento, sino como la concentración, en contenedores miniaturizados, de la inteligencia y la creatividad colectiva de la humanidad. La nueva imagen del planeta sería entonces la de una superficie liberada de lo urbano gracias a que este se condensa en "arcologías" o núcleos urbanos miniaturizados conectados entre sí por rutas eficientes de trenes y aviones. (Soleri, 1970, p.2)

Una pequeña selección de frases define la Arcología según Soleri

"El concepto es el de una estructura llamada arcología, o arquitectura ecológica. Tal estructura asumirá el papel del paisaje natural en tanto constituirá la nueva topografía con la que se trabajará. No será una configuración de una superficie, sino una de múltiples niveles. Será un dispositivo habitacional de grandes dimensiones en el que se fracciona el espacio tridimensional en grandes $y$

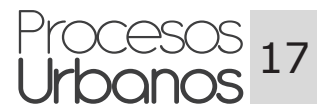


pequeños subespacios, creando su propio clima y su propio paisaje urbano. El concepto de un sistema uni-estructural no es incidental en la organización de la ciudad, es central en ella. Es la totalidad de un organismo biológico lo que se busca en la factura de la ciudad, como son tantas y tan estrictas las analogías entre el funcionamiento de un organismo $y$ la vitalidad de una estructura metropolitana." (Soleri, 1970, p.13)

Además del complejo discurso filosófico de Soleri, los proyectos ilustrativos del principio de la Arcología fueron demostraciones de las posibilidades arquitectónicas de estructuras inmensas, concebidas estéticamente, como condición esencial de su naturaleza. Las dimensiones de cada Arcología eran en su momento colosales: poblaciones de un millón de habitantes, alturas de más de 1.000 metros. Paradójicamente el tamaño de algunas de ellas ha sido superado hoy en edificaciones banales, con grandes despliegues tecnológicos, (v.gr. Dubai) que no aportan nada a una verdadera transformación del hábitat humano.

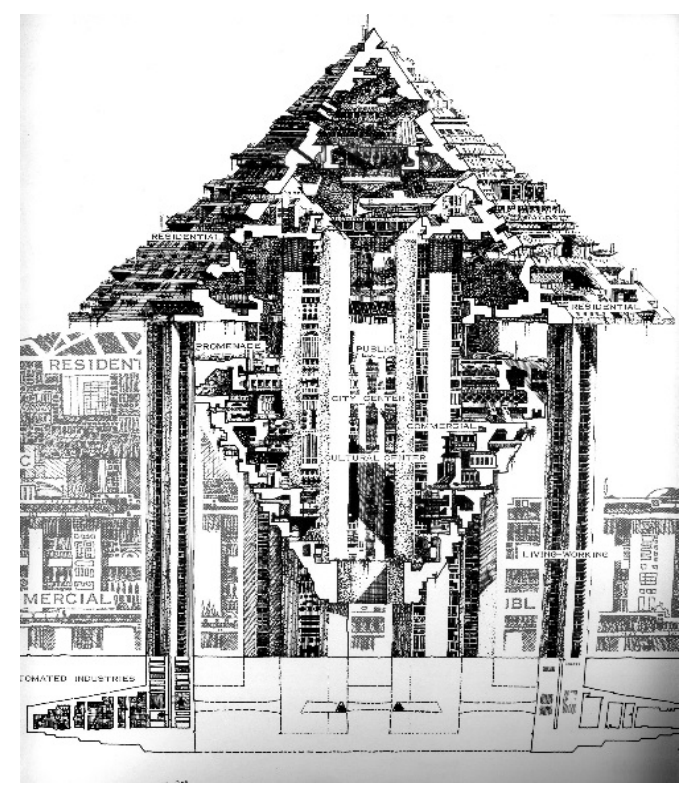

Figura 4. Arcología Babelnoah Fragmento.

Fuente: Soleri, Paolo, Arcology. The City in the Image of Man. M.I.T. Press, Cambridge, 1970.

El contraste entre Friedman y Soleri queda apenas esbozado. Mientras el primero abogaba por un urbanismo indeterminado, en el que las estructuras habitables eran simples estructuras tridimensionales, a la manera de grandes vigas, para Soleri la ciudad debería tener una imagen potente, que contrastara fuertemente con el territorio, que pudiera contener todas las actividades de un grupo humano y cuya meta sería la de potenciar, como ya se dijo, el paso de la materia al espíritu.

Además de las ideas urbanas del Team $X$ y de los futuristas, la ciudad ocupó buena parte de los temas tratados en los últimos cuarenta años del siglo pasado. Distintas lecturas se hicieron y quedaron consignadas en textos tales como La imagen de la ciudad de Kevin Lynch, La arquitectura de la ciudad de Aldo Rossi, La vida cotidiana en el mundo moderno, El derecho a la ciudad y La revolución urbana de Henri Lefevre, La torre de Babel de Ludovico Quaroni, Ciudad collage de Colin Rowe y Fred Koetter, El espacio urbano de Rob Krier, Muerte y vida de las grandes ciudades de Jane Jacobs, Delirious New York de Rem Kolhaas, y muchos otros más. Muchas propuestas y denominaciones aparecieron para contradecir o superar la idea moderna de una ciudad unitaria y funcionalmente articulada. Paralelamente la idea misma de una sociedad unidimensional se sustituyó por la celebración de la multidimensionalidad urbana. Se reconoció, al tiempo con la heterogeneidad social y cultural que habita en las ciudades del mundo, la fragmentación de sus tejidos, la multiplicidad de centralidades y también la multiplicidad de imágenes de ciudad en las mentes ciudadanas. En cierto modo la "torre de Babel" adquirió un cierto sentido de realidad.

\section{La ciudad del siglo XXI: complejidad, multiculturalidad, información.}

No es fácil caracterizar los fenómenos urbanos contemporáneos aparte de situarlos dentro del mundo globalizado o fuera de él. $Y$ esto es bastante relativo. Si bien las ciudades como lugares físicos se arraigan en un territorio, los conocimientos, ideas, imágenes y símbolos que antes se confinaban dentro de sus límites recorren hoy el planeta a través de las redes de información y comunicación las que, en su conjunto, estructuran una forma particular de "cultura urbana expandida". Esta puede hoy entenderse como virtud, como vicio o como algo que va "más allá del bien y del mal", que existe y que hay que entenderlo, bien sea para beneficiarse de él, bien para descartarlo. En cada caso hay defensores y detractores. 
La mirada a la ciudad en lo que va corrido del siglo 21 ha estado a cargo principalmente de autores del campo de las ciencias sociales. Dos temas predominan en sus discursos: la multiculturalidad propia de las grandes ciudades, la heterogeneidad derivada de ello, las múltiples dimensiones de la vida urbana, tanto en la experiencia cotidiana como en las redes comunicativas expandidas gracias a Internet. Autores como Guy Debord, Michel de Certeau, Paul Virilio o Saskia Sassen, incursionan en los mundos urbanos para desentrañar en ellos aquello que sucede o puede suceder. Francisco Jarauta lo resume así: "A lo largo de las últimas décadas la ciudad se ha convertido en una de las problemáticas centrales que atraen la atención de diferentes disciplinas sociales, tales como la sociología, la antropología, la geografía humana, el nuevo urbanismo e incluso la filosofía. Desde perspectivas varias se insiste en analizar las diferentes dimensiones con las que la ciudad contemporánea se construye, se organiza, se administra. En efecto, la ciudad se ha convertido en el laboratorio en el que mejor se experimentan todos aquellos procesos que acompañan a la transformación de las sociedades contemporáneas, marcadas especialmente por nuevas intensidades demográficas y por la tendencia a una creciente concentración urbana." (Jarauta, 2015).

En otro texto Jarauta añade:

\footnotetext{
"Pero, al mismo tiempo, la ciudad se ha convertido en el espacio por excelencia de representación y expresión de las nuevas tensiones sociales, culturales y políticas del mundo contemporáneo. (...) La ciudad es cada vez más el escenario de derivas y flujos, de encuentros y fugas producidos en el territorio que articula los sujetos que la recorren, sus formas de vida, sus necesidades y ansiedades. Las marcas, las señales de diferenciación e identidad o reconocimiento constituyen una economía de lo simbólico que Richard Sennett o Paul Virilio han identificado en su dimensión funcional. Son ellas las que articulan el difícil equilibrio -cada vez más frágil- de las nuevas complejidades sociales. " (Jarauta, 2007, p.6).
}

Marc Augé por su parte, aporta a lo anterior estas observaciones interesantes:

"Las grandes ciudades se definen principalmente por su capacidad de importar o exportar personas, productos, imágenes y mensajes. Espacialmente, su importancia se mide según la calidad y amplitud de la red de autopistas o de las vías ferroviarias que las conectan con sus aeropuertos. Su relación con el exterior se inscribe en el paisaje en el momento mismo en que los centros llamados "históricos" son, cada vez más, un objeto de atracción para los turistas de todo el mundo."

"En las viviendas, casas o apartamentos, el televisor y el ordenador han ocupado el lugar del hogar. Los helenistas nos han enseñado que sobre la casa griega clásica velaban dos divinidades: Hestia, diosa del hogar, en el centro umbrío y femenino de la casa, y Hermes, dios del umbral, que mira hacia el exterior, protector de los intercambios y de los hombres que tenían su monopolio. Hoy en día el televisor y el ordenador han ocupado el lugar del hogar en el centro de la vivienda. Hermes ha sustituido a Hestia" (Auge, 2007, p.15).

Y en otro texto añade:

"La ciudad, la gran ciudad, tiene su lugar en la literatura, en la pintura y hasta en la música; es decir, la ciudad es de manera ejemplar objeto de representaciones de las que podemos hallar una versión modesta e individual en las palabras que suelen decir los habitantes de una ciudad sobre la relación que mantienen con ella, en la historia que los vincula a ella, en los recorridos que realizan por ella en intervalos regulares. Si hoy estamos dispuestos a hablar de "crisis de lo urbano", esto no se debe tal vez simplemente a la circunstancia de los problemas urbanísticos, arquitectónicos y sociológicos que implica o amplifica la extensión de las ciudades, sino más profundamente a que representarse hoy la ciudad se hace más difícil. En este sentido, la crisis de lo urbano remite a una crisis más general de las representaciones de la contemporaneidad". (Augé, 2006, p.146). 


\section{Procesos Urbanos N³ Enero - Diciembre; 2016}

Mientras Jarauta observa el dominio colectivo, el espacio de las derivas y flujos, encuentros y fugas, Auge apunta hacia el mundo interior, el de la vivienda y el de las representaciones. Para ambos autores la ciudad deja de ser un fenómeno físico, para ser ante todo y principalmente un fenómeno social y cultural que se lleva a cabo en espacios indeterminados. La ciudad no es una, sino una acumulación de vivencias y representaciones, ninguna de las cuales puede dar cuenta de su totalidad.

\section{Latinoamérica y Colombia: un capítulo por escribir}

¿Cómo encaja la "ciudad latinoamericana" como idea en estos discursos? Aparte de aquello que se ha instalado en el mundo como el modo de vida urbana "contemporáneo, tal como se lee en Jarauta y Augé y en muchos otros autores, hay particularidades innegables que provienen del largo proceso de su formación, desde tiempos pretéritos hasta el presente. La ciudad latinoamericana como idea y objeto de estudio fue intelectualmente construida en la segunda mitad del siglo XX y esa construcción dio origen a varias vertientes investigativas, una de ellas, la ruta del pasado, la historia urbana, otra, la ruta del presente, la sociología urbana y simultáneamente la teoría y la práctica del urbanismo y la planeación. Innumerables discusiones sobre esta ciudad, hecha de muchas ciudades distintas, se dieron en el seno de encuentros académicos, profesionales y políticos, con visiones radicalizadas entre el desarrollismo y la crítica marxista.

Una obra clásica de la historia urbana en Latinoamérica es el libro de José Luis Romero, titulado Latinoamérica, las ciudades y las ideas, en el que el autor analizó distintos momentos o estadios en el desarrollo de ese inmenso universo urbano. En la Introducción a su libro, Romero expone su intención:

"Este libro intenta responder a la pregunta de cuál es el papel que las ciudades han cumplido en el proceso histórico latinoamericano. Diverso hasta parecer caótico, ese proceso tiene sin duda un hilo conductor. Seguramente es difícil hallarlo porque cierta homogeneidad originaria se ha desvanecido a lo largo de los profundos conflictos que se desencadenaron con las guerras de independencia. Pero ciertas constantes sugieren la posibilidad de que se halle oculto detrás de algunos de los factores que intervienen en el proceso. Para un historiador social no hay duda de que el camino que hay que seguir para encontrarlo es el que transitan las sociedades latinoamericanas a través de las singulares circunstancias en que se construyen y de aquellas, múltiples y a veces oscuras, en que se opera su constante diferenciación. Y en ese camino, el papel que cumplen las ciudades -esto es, las sociedades urbanas y su densa creación- parece ofrecer alguna clave aprehensible en medio de un cuadro muy confuso" (Romero, 1999, p.xxi).

La intención de Romero se desarrolla en siete extensos capítulos que recorren la trayectoria de la ciudad en la construcción de la sociedad latinoamericana. Los títulos son dicientes en relación con su enfoque y contenido: Latinoamérica en la expansión europea; el ciclo de las fundaciones; las ciudades hidalgas de Indias, las ciudades criollas; las ciudades patricias; las ciudades burguesas y las ciudades masificadas. El recorrido da una visión de conjunto a la formación y desarrollo de las ciudades en distintos puntos del territorio latinoamericano. En el último capítulo, Romero trata el tema de las transformaciones urbanas acaecidas en Latinoamérica entre 1930 y 1976, año de la primera edición del libro. La explosión urbana, la metrópoli y los rancheríos y la masificación y estilo de vida son tres de los temas tratados en el capítulo. Un párrafo puede tomarse como indicativo de la mirada de Romero a este fenómeno:

"Ciertamente, las migraciones y las polarizaciones sociales que enseguida se produjeron transformaron a las ciudades en una yuxtaposición de guetos, zonas urbanas poco comunicadas entre sí o con contactos muy superficiales y convencionales. No se necesitaba mucho tiempo para descubrir que en cada uno de ellos se vivía de distinta manera. Y no solo 
era evidente que se diferenciaba el modo de vida de las gentes que vivían en los suburbios aristocráticos del que llevaban los habitantes de los rancheríos: aun dentro de cada uno de esos sectores se apreciaba una diferenciación que parecía más profunda porque estaba a veces velada por ciertas engañosas coincidencias anteriores." (Romero, 1999, p.439).

Esa ciudad, vista por Romero hacia 1976 es, a una escala mayor y más compleja, la que puede encontrarse hoy en América Latina. Pero las transformaciones producidas desde entonces hace que la ciudad en América Latina sea un fenómeno complejo y difícil de abordar. Los escritos de Manuel Castells, en especial La cuestión urbana (1974), e Imperialismo y urbanización en América latina pueden considerarse como clásicos de la sociología urbana marxista de la segunda mitad del siglo $X X$ y en ellos se buscó dar cuenta de los muchos conflictos y contradicciones que se señalaron como parte constitutiva de esos conglomerados urbanos.

La construcción de ideas y discursos sobre la ciudad colombiana se inició en la misma época y ha seguido rutas paralelas a las del discurso latinoamericano: la de la historia urbana, con importantes avances, y la de las ciencias sociales, que ha deambulado a lo largo de muchos senderos, unos más. Otros menos politizados. Planteamientos urbanísticos particulares han sido escasos, y han sido guiados por las oscilaciones del discurso moderno y de sus detractores. El crecimiento explosivo causado por las migraciones campesinas fue uno de los tantos factores que pusieron en tela de juicio la validez de esos enfoques. Más allá de los discursos, las ciudades han seguido su transcurso alcanzando situaciones cada vez más complejas, cuya resolución a través de un plan parece bastante lejana.

Un trabajo de carácter histórico y de gran espectro sobre la ciudad colombiana es el libro titulado precisamente La Ciudad Colombiana, del urbanista e historiador francés Jacques Aprile-Gniset, publicado en 1991. En los dos primeros tomos, el autor planteó su visión de conjunto del proceso histórico, el primero sobre el ámbito de la ciudad prehispánica, de conquista e indiana y el segundo, de la ciudad de los siglos XIX y XX. A ellos añadió posteriormente dos tomos más, dedicados a estudios de caso específicos. El ámbito territorial y cronológico es muy amplio, como lo es también la amplitud de la mirada del autor. Este es un libro de historia urbana que excede los límites mismos de la disciplina.

A este estudio se puede añadir una extensa lista de estudios históricos específicos de diversas ciudades y poblaciones colombianas que dan cuenta de procesos particulares en mayor o menor detalle. En la segunda mitad del siglo XX se realizaron varios estudios demográficos y morfológicos de ciudades colombianas, orientados principalmente hacia el ordenamiento del territorio y la planeación. Entre ellos se encuentran, entre otros, los de Ramiro Cardona y la Corporación Centro Regional de Población, los de Humberto Molina en el CPU de la Universidad de Los Andes, el CID de la Universidad Nacional y el Centro Hábitat de la Universidad Nacional sede de Medellín. Luego de un cierto auge, el estudio de la ciudad colombiana contemporánea decreció y aún se desconocen sus múltiples fisonomías.

\section{Epílogo}

Un párrafo de Francisco Jarauta permite sintetizar y concluir el contenido de este artículo:

"La ciudad constituye el horizonte, la forma de vida de las sociedades contemporáneas. A lo largo de los dos últimos siglos, desde los inicios de la Revolución Industrial, las ciudades sufrieron transformaciones cualitativas. El siglo XIX fue testigo del emerger de las metrópolis, como París, Londres o Berlín. Más tarde fueron las ciudades americanas, como Chicago o Nueva York -las ciudades verticales de Le Corbusier-, las que marcaron la transformación de una estructura y un concepto que ha prevalecido a lo largo del siglo $X X$. 
Hoy asistimos a un panorama mucho más complejo. Factores demográficos, migratorios, económicos y sociales, hacen que el $75 \%$ de la población del planeta viva en grandes $y$ abiertos espacios urbanos. Lagos, México D.F., Shangai, Bombay o Tokio.., aparecen hoy como realidades sociales más cercanas a lo que ha venido a definirse por Rem Koolhaas como villes generiques que a las metrópolis históricas. Son la nueva dimensión de una ciudad sin límites, expansiva, que se proyecta como ciudad global en la que se concentran los nuevos flujos migratorios dando lugar a una complejidad metametropolitana, que precisan otras lecturas e intervenciones políticas. (Jarauta, 2007, p.5).

La ciudad ya no es lo que solía ser. A lo largo del siglo $X X$ se realizaron incontables esfuerzos por explicarla, moldearla física y socialmente, e incluso evadirla. El Urbanismo nació, creció, se expandió y en cierta forma decayó como el instrumento ideal para enfrentar el presente y el futuro de las ciudades. La ciudad como objeto de estudio ha atraído la atención no solo de urbanistas y arquitectos sino, también de filósofos y científicos sociales cuyos aportes han puesto de presente lo que existe en los espacios construidos.

A lo largo de un siglo, el discurso sobre las ciudades ha seguido o se ha anticipado a sus realidades. Las denominaciones han cambiado y en cierta forma hoy solo subsisten tres de ellas: ciudades, metrópolis y megalópolis. Ninguna de ellas es precisa, todas son ambiguas. La complejidad está presente en todas ellas. La manera de mirarlas conserva todavía algo de admiración, algo de rechazo y algo de aceptación de sus múltiples realidades. Hay quienes pretenden organizarlas espacialmente, hay quienes prefieren que sean ellas mimas las autoras de su propio destino.

\section{Referencias}

Aprile-Gniset, J. (1991a) La ciudad colombiana, volúmenes 1 y 2 . Bogotá. Fondo de Promoción de la Cultura, Banco Popular.

Aprile-Gniset, J. (1991b) La ciudad colombiana, volumen 3. Cali, Editorial Universidad del Valle.

Aprile-Gniset, J. (1991c) La ciudad colombiana, volumen 4. Cali, Programa Editorial Universidad del Valle.

Auge, M. (2006) Hacia una antropología de los mundos contemporáneos. Barcelona, Gedisa editorial.

Auge, M. (2007) El antropólogo y la ciudad. En: AA.VV. El futuro de las ciudades. Murcia, Foro de la Mundialización.

Castells, M. (1973) Imperialismo y urbanización en América Latina. Barcelona, Gustavo Gili.

Castells, M. (1974) La cuestión urbana. México, Siglo XXI Editores

Doxiadis, C. A. (1970). Ekistics, the science of human settlements. Science, 170(3956), 393-404.

Friedman, Y. (1965) El urbanismo espacial en: Ragon, Michel. Los visionarios de la arquitectura. México, Siglo XXI Editores. 
Saldarriaga, A. - Acerca de las ciudades: la mirada de ayer y de hoy.

Gottman, J. (1961) Megalopolis, the Urbanized Northeastern Seaboard of the United States. Cambridge, MIT Press

Gottman, J. (1968) Mankind is Reshaping its Habitat. En : Elias, C.E. Gillies, J. Y Riemer, S. Editores. Metropolis: values in conflict. Belmont, Wadsworth Publising Co. Traducción: A.S.R.

Jarauta, F. (2007) Presentación. En: AA.VV. El futuro de las ciudades. Murcia, Foro de la Mundialización.

Lynch, K. (1960) The Image of the City. Cambridge. MIT Press.

Lynch, K. (1968) The Pattern of the Metropolis. En : Elias, C.E. Gillies, J. Y Riemer, S. Editores. Metropolis: values in conflict. Belmont, Wadsworth Publising Co. Traducción: A.S.R.

Mumford, L. (1968) The Design of the City. En : Elias, C.E. Gillies, J. Y Riemer, S. Editores. Metropolis: values in conflict. Belmont, Wadsworth Publising Co. Traducción: A.S.R.

Romero, J. L. (1999) Latinoamérica: las ciudades y las ideas. Medellín. Editorial Universitaria de Antioquia.

Rowe, C. ; Koetter, F. (S.f.) Collage City. Barcelona, Gustavo Gili.

Rossi, A. (1971) La arquitectura de la ciudad. Barcelona, Gustavo Gili.

Schorske, C. E. (2000) La idea de ciudad en el pensamiento europeo: de Voltaire a Spengler. Bogotá. Maestría en Historia y Teoría del Arte y la Arquitectura. Textos 3, Bogotá, Facultad de Artes, Universidad Nacional de Colombia. Traducción. Jorge Mejía.

Simmel, G. (1968) The metropolis and mental life. En : Elias, C.E. Gillies, J. Y Riemer, S. Editores. Metropolis: values in conflict. Belmont, Wadsworth Publising Co. Traducción: A.S.R.

Smithson, Alison (Ed). (1968) Team 10 Primer. Cambridge. The MIT Press.

Soleri, P. (1970) Arcology. The City in the Image of Man. Cambridge, MIT Press.

Soleri, P. (1984) Arcosanti. An Urban Laboratory. San Diego, Avant Books.

Van Eyck, A. (1968) Wheels or no wheels, man is essentially a pedestrian. En: Smithson, A. Team 10 Primer. Cambridge. The MIT Press. 